
\title{
Modelo de cuidado transicional à mãe da criança com
cardiopatia congênita*
}

\author{
Model of maternal transitional care to mothers of a child with congenital heart disease
}

Modelo de atención transicional a la madre del niño con cardiopatía congénita

\author{
Daniele Laís Brandalize Rocha ${ }^{1}$, Ivete Palmira Sanson Zagonel ${ }^{2}$
}

\begin{abstract}
RESUMO
Objetivos: Desvelar o significado da vivência materna no processo de transição de doença-saúde do filho com cardiopatia congênita; identificar os comportamentos apresentados pela mãe durante a vivência e propor um modelo de cuidado transicional à mãe, à luz da teoria de enfermagem de Roy. Métodos: Pesquisa qualitativa, desenvolvida por meio do método de pesquisa-cuidado, com entrevista semiestruturada de 10 mães que acompanhavam seus filhos no pós-operatório de cirurgia cardíaca em hospital pediátrico. Resultados: Pela análise de conteúdo de Bardin foram apreendidas seis Unidades de Contexto e onze Unidades de Significação que revelaram alterações sofridas pelas mães em sua vida pessoal e familiar durante a vivência materna do processo de transição de saúde-doença do filho. Conclusões: O enfermeiro, ao conhecer o processo de transição vivenciado pela mãe auxilia a mobilizar os recursos que possui para o enfrentamento e adaptação à nova situação pela aplicação do modelo de cuidado transicional.

Descritores: Cuidados de enfermagem; Cuidado da criança; Cardiopatias congênitas, Cuidado pós-operatório; Enfermagem pediátrica
\end{abstract}

\begin{abstract}
Objectives: To understand the meaning of maternal experience in the health-illness transition of a child with congenital heart disease, to identify maternal behaviors during this experience, and to propose a model of maternal transitional care guided by the Roy's adaptation nursing theory. Methods: A qualitative research design was used to conduct this study. Data were collected through semi-structured interview with 10 mothers who stayed with their children in the postoperative period of cardiac surgery in a pediatric hospital. Results: Bardin's (1991) content analysis approach led to the identification of six units of context and eleven units of meaning regarding maternal personal and family experience during the health-illness transition of a child with congenital heart disease. Conclusions: Understanding the meaning of maternal experience in the health-illness transition of a child, nurses can mobilize resources and apply the model of maternal transitional care, which may be useful in helping mothers to deal with and adapt to the new situation of health-illness transition of a child with congenital heart disease.
\end{abstract}

Keywords: Nursing care; Child care; Heart defects, congenital; Postoperative care; Pediatric nursing

\section{RESUMEN}

Objetivos: Develar el significado de la vivencia materna en el proceso de transición de enfermedad-salud del hijo con cardiopatía congénita; identificar los comportamientos presentados por la madre durante la vivencia y proponer un modelo de cuidado de transición a la madre, a la luz de la teoría de enfermería de Roy. Métodos: Investigación cualitativa, desarrollada por medio del método de investigación-cuidado, con entrevista semi-estructurada a 10 madres que acompañaban a sus hijos en el post-operatorio de cirugía cardíaca en un hospital pediátrico. Resultados: Por el análisis de contenido de Bardin (1991) se elaboraron seis Unidades de Contexto y once Unidades de Significado que revelaron alteraciones sufridas por las madres en su vida personal y familiar durante la vivencia materna del proceso de transición de saludenfermedad del hijo. Conclusiones: El enfermero, al conocer el proceso de transición experimentado por la madre ayuda, por medio de la aplicación del modelo de atención transicional, a poner en movimiento los recursos que posee para el enfrentamiento y adaptación a la nueva situación.

Descriptores: Cuidados de enfermería; Cuidado del niño; Cardiopatías congénitas; Cuidado postoperatorio; Enfermería pediátrica

\footnotetext{
* Artigo extraído da Dissertação de Mestrado "O Cuidado de enfermagem à mãe na vivência da transição de saúde-doença do filho com cardiopatia congênita", apresentada ao Programa de Pós-Graduação em Enfermagem (Mestrado) da Universidade Federal do Paraná - UFPR - Curitiba (PR), Brasil.

${ }^{1}$ Mestre em Enfermagem; Professora da Faculdades Pequeno Principe (FPP) - Curitiba, (PR), Brasil.

${ }^{2}$ Doutora em Enfermagem; Professora do Programa de Pós-Graduação em Biotecnologia Aplicada à Saúde da Criança e do Adolescente da FPP. Coordenadora do Curso de Enfermagem da FPP. Coordenadora do Núcleo de Estudos, Pesquisa e Extensão em Enfermagem (NEPEE). Curitiba, (PR), Brasil.
} 


\section{INTRODUÇÃO}

A doença representa um impacto na vida das pessoas e, quando envolve uma criança e esta necessita da hospitalização, se torna uma vivência marcante, envolvendo também a família. A criança de forma inesperada é separada dos familiares e de sua rotina, o mundo lhe parece desaparecer. Esta experiência acarreta desgaste físico e psicológico para os familiares, que podem reagir de diferentes formas, sendo freqüente o aparecimento do medo, da insegurança, da depressão, entre outros ${ }^{(1)}$.

A partir dessa realidade, elaboramos o presente artigo, como extrato da dissertação de mestrado, que envolveu mães que vivenciaram a transição de doença-saúde do filho hospitalizado com cardiopatia congênita ${ }^{(2)}$.

A realização de pesquisas de enfermagem com famílias que possuem um filho com anomalia congênita, neste caso a cardiopatia, é de grande importância, pois possibilita melhor compreensão da experiência no processo de cuidar da criança em seu cotidiano. Porém, além de compreender a experiência da família, são necessários estudos que também visem à intervenção de enfermagem nessas situações, pois elas podem instrumentalizar o enfermeiro para o cuidado ${ }^{(3)}$. Desta forma, consideramos a relevância deste estudo pois, além de refletir sobre a vivência da mãe no processo de transição de doença-saúde do filho hospitalizado com cardiopatia congênita, aponta para a importância do cuidado transicional, isto é, o cuidado de enfermagem diante do processo de transição, articulado à Teoria de Adaptação de Roy, cujos conceitos, aliados aos de transição, direcionam o olhar do enfermeiro para o cuidado à mãe. Acreditamos que o modelo de cuidado proposto neste estudo aproxima o cuidado de enfermagem das reais necessidades da mãe durante esse processo de transição.

\section{REFERENCIAIS TEÓRICOS: CUIDADO TRANSICIONAL E MODELO ADAPTATIVO DE ROY}

Quando a mãe recebe o diagnóstico da cardiopatia congênita do filho, antes ou após o seu nascimento, tem início, para ela, a vivência do processo de transição de doença-saúde do filho, o qual se desenvolve pelas inúmeras transformações, a partir da notícia de que seu filho possui a doença. Criança com cardiopatia congênita apresenta uma malformação na estrutura do coração ou dos grandes vasos, presente por ocasião do nascimento, podendo representar um defeito cardíaco individual ou uma combinação de defeitos ${ }^{(4)}$.

Passar por essa experiência coloca a mãe diante da vivência da transição, a qual é definida como um processo de mudança, passagem, movimento, de um estado, situação ou experiência para outro, fazendo com que o indivíduo passe por enfrentamentos, tomando posições e atitudes frente à nova situação vivida ${ }^{(5)}$. O processo de transição vivenciado pela mãe diante da doença do filho com cardiopatia congênita traz consigo o fato de ter, não somente um filho doente, mas um filho com uma doença com características de ser grave, desconhecida, permeada de símbolos e significações incertos, além da necessidade de enfrentar a intervenção cirúrgica para sua correção.

O enfermeiro, ao conhecer o processo de transição e suas conseqüências para a mãe que a experiencia, sujeito deste estudo, pode atuar de maneira antecipatória para prevenir, promover ou mesmo intervir de forma terapêutica frente aos efeitos dessa transição, tendo como objetivo restabelecer a harmonia e a estabilidade perdida. Essa intervenção de enfermagem, diante do processo de transição, é chamada de cuidado transicional ${ }^{(5)}$.

Neste estudo, articulamos aos conceitos de transição a Teoria da Adaptação, proposta por Roy ${ }^{(6)}$, pois consideramos que o processo de transição de doençasaúde que a mãe do filho com cardiopatia congênita passa, guarda proximidade com as idéias e os conceitos de Roy, uma vez que em suas reflexões teóricas, trata do conceito de adaptação, aspecto importante e imprescindível ao enfocar o referencial de transição.

De acordo com Roy, a pessoa, como um sistema, tem a capacidade de se adaptar e criar mudanças no meio ambiente. Sendo um sistema, a pessoa recebe estímulos, dentre eles o focal, que é o estímulo interno ou externo que constitui o maior grau de mudança, gerando um forte impacto; os estímulos contextuais, que são todos os outros estímulos presentes na situação que contribuem para o efeito do estímulo focal e os estímulos residuais, que são os fatores cujos efeitos na situação atual não são centrais e a pessoa pode não ter consciência da influência destes fatores. A vivência dos estímulos é simultânea, ocorrem sem uma ordem aparente, sem que a pessoa se dê conta que estão atuando ${ }^{(()}$.

Neste estudo, a cardiopatia congênita do filho é considerada como estímulo focal para a mãe, sendo uma mudança negativa acerca do estado de saúde do mesmo, que a confronta no sentido desta ter que enfrentar essa nova situação e apresentar uma resposta. $O$ conhecimento que ela tiver sobre a doença e o seu tratamento, o suporte emocional, psicológico, espiritual e social vão agir como estímulos contextuais, podendo influenciar de forma positiva ou negativa sobre o estímulo focal. Os estímulos residuais podem ser alguma experiência que ela tenha vivido no passado com relação à doença (sua ou de algum familiar) e que esteja adormecida.

Cada pessoa, como um sistema adaptativo, tem um nível de adaptação, o qual é determinado por processos de controle, também chamados de mecanismos de enfrentamento reguladores (fisiológico) e cognatos 
(sentimentos e mobilizações emocionais) os quais são subsistemas da pessoa como um sistema adaptativo. Sendo assim, ao receber os estímulos, iniciam na pessoa processos de controle, em que os mecanismos de enfrentamento irão determinar os comportamentos a serem expressos, podendo ser adaptáveis ou não ${ }^{(6)}$.

A investigação do comportamento da pessoa deve ser realizada nos quatro modos adaptativos identificados por Roy, os quais resultam dos mecanismos de controle reguladores e cognatos, citados como, fisiológico, autoconceito, função de papel e interdependência. A mobilização dos quatro modos de adaptação é que configuram a intensidade do processo de transição vivenciado pela mãe, pois se alteram de acordo com a experiência singular de cada sujeito com maior ou menor intensidade.

O modo de adaptação fisiológico é facilmente percebido, pois envolve as necessidades básicas do subsistema regulador, porém os demais modos são subjetivos e vivenciados de maneira diferente, mesmo diante do mesmo estímulo. $\mathrm{O}$ modo de autoconceito está relacionado aos aspectos psicológicos e espirituais da pessoa, envolve o eu físico e o eu pessoal; o modo de função de papel envolve os padrões de interação social e o modo de interdependência, os relacionamentos interpessoais, as necessidades afetivas, como valor humano, afeição, amor, afirmação().

O enfermeiro, ao conhecer o processo de transição de doença-saúde que a mãe está vivenciando e as repercussões que este traz à sua vida, por considerá-la como um sistema adaptável, observará o seu comportamento externo nos quatro modos de adaptação, e verificará se ela está se adaptando ou não ao ambiente em mudança, isto é, se o comportamento é adaptável ou ineficaz.

Diante da situação de enfrentamento da doença do filho, a mãe está exposta a distintos estímulos, os quais serão confrontados com os modos de adaptação e resultarão em comportamentos adaptativos ou não. Somente com o envolvimento do enfermeiro, ciente destas significativas transformações a que a mãe passa é possível auxiliar, para alcançar um comportamento adaptativo e, portanto, menos traumático.

A partir dessa contextualização propusemos como objetivos deste artigo, desvelar o significado, para a mãe, da vivência do processo de transição de doença-saúde do filho com cardiopatia congênita; identificar os comportamentos apresentados pela mãe durante a vivência e propor um modelo de cuidado transicional à mãe, à luz da teoria de enfermagem de Roy.

\section{MÉTODOS}

Para o desenvolvimento do estudo, utilizamos a pesquisa qualitativa, por meio do método de pesquisacuidado. A pesquisa-cuidado é "uma abordagem de pesquisa coerente com a natureza da enfermagem, integrando a pesquisa e o cuidado como elementos complementares à atuação do enfermeiro"(7).

A pesquisa-cuidado percorre etapas para a sua efetivação, que podem ser estabelecidas conforme se processa o encontro entre o ser pesquisador-cuidador e ser pesquisado-cuidado: aproximação do fenômeno de estudo; encontro com o ser pesquisado-cuidado; estabelecimento das conexões da pesquisa, teoria e prática do cuidado; afastamento do ser pequisador-cuidador e ser pesquisado-cuidado; análise do apreendido.

A aproximação do fenômeno de estudo ocorreu durante a trajetória profissional na UTI cardíaca pediátrica da primeira autora, que percebeu a necessidade de realizar o estudo com mães de crianças ali hospitalizadas.

A fase de encontro com o ser pesquisado-cuidado corresponde ao momento da interação, em que como pesquisadora-cuidadora, a autora do estudo, desvelou o que desejava pesquisar e tomou decisões conjuntas com o ser cuidado, a partir das necessidades levantadas e validadas por ambos. Nessa etapa, são descritos o local, os sujeitos, a técnica de coleta de informações e os aspectos éticos. O local escolhido para a realização do estudo foi a unidade de cardiologia, incluindo a UTI e enfermaria de um hospital pediátrico de grande porte na cidade de Curitiba (PR), com especialidades exclusivas para atendimento a crianças e adolescentes e serviços de alta complexidade, localizado na região leste do Estado do Paraná, dispondo de 345 leitos.

Participaram deste estudo, 10 mães que acompanhavam seus filhos hospitalizados, seguindo os seguintes critérios de inclusão: que tivessem filho no pós-operatório para correção de defeito cardíaco congênito e que aceitassem participar da pesquisa-cuidado. O primeiro critério de inclusão justifica-se por atender ao primeiro objetivo do estudo que é desvelar o significado sobre a vivência materna no processo de transição de doença-saúde do filho com cardiopatia congênita, pois consideramos que a vivência da mãe neste processo de transição de doença-saúde do filho com cardiopatia congênita abrange todas as etapas percorridas com o filho, desde a descoberta da doença, o tratamento cirúrgico e a recuperação pós-operatória em unidade de terapia intensiva e em unidade de internação cardiológica. Consideramos que, em cada um destes momentos, a mãe sofre modificações intensas para enfrentar e se adaptar à nova situação vivida.

Para a coleta das informações foi utilizada a entrevista semi-estruturada, tendo como questão de pesquisa: o que significa para você ter um filho com doença no coração de nascença, que fez uma cirurgia e está/esteve internado na UTI? Após terem sido explicados os objetivos da pesquisa e as mães terem aceito participar do estudo, assinaram o Termo de Consentimento Livre e Esclarecido. Ainda nesta etapa, foram atendidos os princípios éticos, 
de acordo com a Resolução n. ${ }^{\circ}$ 196/96(8). Em atendimento à legislação vigente, o projeto foi aprovado pelo Comitê de Ética da instituição hospitalar (Número 0361-06).

A terceira fase, de estabelecimento das conexões da pesquisa, teoria e prática do cuidado, realiza as conexões entre a pesquisa (coleta das informações pelo método de pesquisa-cuidado), a teoria (referencial teórico da teoria de Roy e de transição) e a prática (cuidado efetivado). A partir das falas das mães, buscava-se desvelar o significado do processo de transição de doença-saúde vivenciado por elas, ao mesmo tempo em que eram cuidadas, pois dessa forma, foi possível a aplicabilidade do cuidado transicional. A concretização do cuidado, denominado transicional, envolveu os conceitos e princípios da transição vivenciada e dependeu da situação que o pesquisador e ser pesquisado experienciavam. O cuidado estabeleceu-se de diferentes formas, ouvindo, olhando, estando presente, tocando, respeitando comportamentos e atitudes, estabelecendo relacionamento de confiança, facilitando o enfrentamento de situações e habilitando para a adaptação ao papel que estava se delineando a partir das vivências da mãe $e^{(7)}$.

A fase de afastamento do ser pequisador-cuidador e ser pesquisado-cuidado foi preparada durante toda a trajetória metodológica, para que ao final dos encontros o ser pesquisado-cuidado estivesse preparado para o afastamento do ser pesquisadora-cuidadora, para então, iniciar a análise do material apreendido. Nesse sentido, ao iniciar a aproximação, a pesquisadora-cuidadora explicou sobre a pesquisa e seus objetivos, descrevendo claramente as etapas, considerando a aproximação, o cuidado a ser prestado e o encerramento do encontro.

A última etapa envolve a análise do apreendido, o significado dos discursos das mães, as informações, as quais foram analisadas com o olhar no referencial teórico adotado sobre a teoria de Roy, no referencial de transição e na análise de conteúdo de Bardin. A análise de conteúdo pode ser definida como um conjunto de técnicas de análise da comunicação que visa obter, por procedimentos sistemáticos e objetivos de descrição do conteúdo das mensagens, indicadores que permitem inferir conhecimentos relativos às condições de produção/recepção destas mensagens ${ }^{(9)}$.

Para a análise de conteúdo, seguimos os passos: préanálise: nesta fase o material coletado foi transcrito e realizada leitura flutuante; exploração do material: organizamos o material coletado em Unidades de Contexto e Significação e Tratamento dos resultados obtidos e interpretação em que os resultados brutos foram tratados de maneira a tornarem-se significativos.

\section{RESULTADOS}

Após minuciosa análise do conteúdo das expressões das mães chegamos a seis Unidades de Contexto e onze Unidades de Significação, as quais revelaram as intensas alterações sofridas pelas mães na vida pessoal e familiar durante a vivência do processo de transição de doença-saúde do filho.

A seguir, passamos a descrever duas Unidades de Contexto e as respectivas Unidades de Significação. A seleção de duas das Unidades de Contexto, para este artigo, deve-se ao fato da análise ser extensa e não comportar sua totalidade. Descrevemos a Unidade de Contexto que mais revelou comportamentos ineficazes da mãe, relacionados ao modo de adaptação função de papel com duas Unidades de Significação: Mudança de papéis durante a doença e hospitalização do filho e o processo de assumir e desenvolver um novo papel na família. A outra Unidade de Contexto escolhida apresenta comportamentos eficazes relacionados interdependência, demonstrando respostas adaptativas neste modo, com uma Unidade de Significação, a rede de apoio social contribuindo no cuidado ao filho doente e hospitalizado.

A Unidade de Contexto: função de papel: as dificuldades vividas pela mãe a partir da doença do filho e a Unidade de Significação: Mudança de papéis durante a doença e hospitalização do filho revelaram que as mães têm consciência dos papéis que desempenham e das alterações que os mesmos sofrem com a hospitalização do filho. Os papéis foram definidos como as unidades de funcionamento da sociedade e cada papel existe em relação com um outro. Associado a cada papel está um conjunto de expectativas sobre a forma como a pessoa se comporta( ${ }^{(0)}$.

Com relação ao emprego, muitas afirmaram terem se afastado e algumas até tiveram que abandonar o trabalho, e também os estudos, o que interferiu na renda familiar. Sabe-se que, ao longo de todo o período da vida, os indivíduos têm necessidade de mudar de papéis e há um comportamento adaptável, quando ocorre um movimento positivo em direção ao objetivo do domínio do $\operatorname{papel}^{(6)}$.

En ia pra faculdade, ia trabalhar, agora com filho, ainda mais, se ele tivesse saúde seria diferente, ele podia ficar na creche, en ia trabalhar tranqüila. Podia pagar alguém pra ficar com ele pra eu ir pra faculdade, mas eu tenho medo, de outra pessoa (Girassol).

Com relação ao cuidado da casa, muitas tiveram que diminuir ou até abandonar os afazeres domésticos, já que elas permanecem mais tempo no hospital do que em casa e, como muitas delas são provenientes de outras cidades, deixam a casa aos cuidados do marido ou de algum familiar próximo ou até mesmo sem cuidados no período em que estão afastadas. Ocorre o distanciamento do papel quando a pessoa tem o conhecimento e a experiência para desempenhar os comportamentos associados ao papel, mas apenas o faz quando for absolutamente necessário, ou quando não existe mais ninguém à sua volta para desempenhar as tarefas ${ }^{(6)}$. 
Já faz muito tempo que en deixei [a organização da casa] assim, eu organizo tudo e tal, mas primeiro é a minha filha (Amor Perfeito).

Depois que eu soube que ele tem problema no coração minha vida mudou, eu só fico com ele no hospital, minha vida não é mais normal, eu não fico mais em casa, é difícil eu conviver em casa (Violeta).

A Unidade de Significação: O processo de assumir e desenvolver um novo papel está relacionado aos cuidados com a familia durante o período de doença e hospitalização do filho. Percebemos que o papel de esposa e mãe [quando tem outros filhos em casa], fica prejudicado. Ao mesmo tempo em que precisam ficar no hospital com o filho, se preocupam e sentem, por não poder cuidar dos demais filhos que ficaram em casa. Nem sempre a pessoa faz uma escolha consciente quando assume um novo papel, pois são papéis impostos ao indivíduo pelas circunstâncias e pelo ambiente ${ }^{()}$.

A família ficon de lado. Porque eles ficaram pra lá, não tem como cuidar deles. É difícil, é difícil porque eu sou só uma. Não tem como ficar lá e aqui ao mesmo tempo, às vezes eu telefono, é mais eles que vem pra cá, mas eles também compreendem (Íris).

A Unidade de Contexto: a interdependência nas relações: apoio para a mãe no momento de doença e hospitalização do filho e a Unidade de Significação: A rede de apoio social contribuindo no cuidado ao filho doente e hospitalizado permitem constatar a interdependência nas relações familiares, percebendo-se a mobilização familiar diante da doença e hospitalização do filho. A interdependência é definida como as relações mais próximas das pessoas, é um modo social pelo qual as necessidades são satisfeitas por meio da interação social e o objetivo dessas relações é alcançar a adequação afetiva ${ }^{()}$. A família "é necessária para a produção de respostas adaptativas nos modos propostos no modelo de adaptação"(10).

A minha família me ajudou muito a ter calma [...]. Eu me sinto muito apoiada pela minha família, pelo meu marido, pelo pessoal do hospital. Eu tenho uma confiança. Quando eu preciso de ajuda, eu tenho a família e o pessoal aqui pra ajudar também (Margarida).

As mães têm grande confiança na equipe multiprofissional e a tem como apoio, suporte emocional, com quem dividem seus sentimentos e emoções. Ao longo do tempo em que permanecem no hospital, as mães desenvolvem laços de amizade e se sentem apoiadas pela equipe. As amizades são importantes para a pessoa adaptável e é através das amizades que a adequação afetiva é atingida( ${ }^{(6)}$.

[...] as enfermeiras, conversando com elas, pergunto e todo o pessoal ali, me dá apoio, aqui eu converso com todo mundo, com as enfermeiras, com os médicos. Elas [enfermeiras] conversam comigo, desabafam, eu desabafo, elas brincam, dai eu também fico animada, porque elas brincam, sożinho não dá (Íris).
As mães, em sua maioria, têm as outras mães como fonte de apoio, com quem podiam trocar e compartilhar experiências, receberem palavras de ânimo e, assim, se fortalecerem mutuamente, pois estão passando por situações semelhantes e, acabam encontrando uma forma de se conformar e ter uma melhor aceitação, pois percebem que não são as únicas a viverem tal situaçã̃o ${ }^{(11)}$.

Acho que en recebo apoio das outras mães, que nem aquela senhora que tava do meu lado, ela conversou comigo, me deu bastante apoio, então a gente tá nesse lugar, mas existe também pessoas que dá apoio pra gente, pessoas queridas (Violeta).

\section{O MODELO DE CUIDADO TRANSICIONAL ÀS MÃES}

Considerando que a vivência materna diante da cardiopatia congênita do filho é marcada por profundas mobilizações e mudanças, evidenciadas por manifestação de sentimentos com aflição, ansiedade e insegurança com o ambiente novo e desconhecido, que é o hospital e pelas incertezas que cercam o diagnóstico de doença cardíaca. E que as mudanças geradas no comportamento da mãe em muito ajudaram a compreender as estratégias de enfrentamento e adaptação ao processo de transição que vivenciam e a perceber a lacuna no cuidado desempenhado pelo enfermeiro a essas mães, propomos um modelo de cuidado transicional que atenda às suas reais necessidades.

Dessa forma, o modelo de cuidado transicional à mãe, proposto neste estudo, está articulado aos quatro modos de adaptação de Roy, com vistas a proporcionar ao enfermeiro, um método de trabalho aplicado de forma individual às mães, com o objetivo de cuidar, de atender às suas necessidades, de ajudá-las nesse momento de transição a atingir a adaptação frente à nova situação.

O modelo segue os passos do processo de enfermagem, conforme descritos na Teoria da Adaptação de Roy, o qual consiste em seis passos (Figura 1).

Avaliação dos comportamentos: o enfermeiro, no primeiro passo do processo de enfermagem, deve recolher dados sobre o comportamento da mãe e o estado atual de adaptação. No modo fisiológico, deve observar e investigar as respostas fisiológicas que a mãe está apresentando, relacionadas à nutrição, sono e repouso, eliminação. No modo do autoconceito, deve buscar descobrir como a mãe está se sentindo frente a essa situação e se essas questões têm gerado alguma forma de distúrbio, em seu eu físico, relacionado à sua imagem corporal, e em seu eu pessoal, referente às suas características, expectativas e valores. No modo de função do papel, deve identificar como a mãe está se relacionando com as pessoas ao seu redor, como se conforma a rede de apoio familiar e social, e se está havendo algum déficit em seu relacionamento social. No modo de 
interdependência, deve descobrir se as necessidades afetivas da mãe estão sendo preenchidas, se está em déficit de afeição, amor e afirmação, deprimida ou triste, se está passando por períodos de isolamento, solidão e alienação.

Avaliação dos estímulos: após avaliar os comportamentos, deve avaliar os estímulos externos einternos que estão influenciando o comportamento da mãe em cada modo adaptável. Depois de identificados os estímulos, eles devem ser classificados em focais, contextuais e residuais. Ao avaliar o estímulo focal, o enfermeiro analisa o impacto, na mãe, da descoberta da doença cardíaca congênita do filho, com os sentimentos que são mobilizados, a trajetória percorrida desde a descoberta da doença até a hospitalização e cirurgia, a expectativa futura sobre a sua recuperação e os sentimentos por ela vivenciados após a cirurgia.

$\mathrm{Na}$ avaliação do estímulo contextual, o enfermeiro procura verificar como a mãe associa a cardiopatia congênita com a gravidez e o nascimento do filho. Na avaliação dos estímulos residuais o enfermeiro busca experiências passadas de situações similares já vivenciadas pela mãe, ou mesmo os resultados da experiência atual.

Diagnósticos de enfermagem: após avaliar os comportamentos da mãe e os estímulos que estão influenciando, passa para a terceira fase no processo, em que o enfermeiro estabelece os diagnósticos de enfermagem. Uma das formas estabelecidas para a definição de um diagnóstico de enfermagem para a mãe envolve posicionar o comportamento, juntamente com os estímulos mais relevantes. Por exemplo, a mãe apresenta os comportamentos de agitação, insônia, nervosismo e apreensão. Todos estes comportamentos indicam ansiedade. Eles resultam de um estímulo focal, que é a notícia da doença do filho. Dessa forma, o diagnóstico de enfermagem formulado é ansiedade relacionada ao impacto da notícia da doença do filho. Assim, o enfermeiro deve formular todos os diagnósticos de enfermagem relacionados aos comportamentos da mãe e aos estímulos que a influenciam.

Estabelecimento de objetivos: após os diagnósticos de enfermagem serem formulados, o enfermeiro estabelece os objetivos que, consistem na determinação de afirmações claras de resultados comportamentais esperados, a partir dos cuidados de enfermagem para a mãe. Seguindo o diagnóstico de enfermagem formulado anteriormente: ansiedade relacionada ao impacto da notícia da doença do filho, o objetivo esperado pelos cuidados de enfermagem será a mãe apresentar menos ansiedade, calma e controle, à medida que consiga enfrentar e se adaptar à nova situação vivida.

Intervenções: a partir do estabelecimento dos objetivos relativos aos comportamentos que irão promover a adaptação, o enfermeiro determina como intervir para auxiliar a mãe a atingir estes objetivos. $\mathrm{Na}$ intervenção, o enfermeiro pode alterar, aumentar, diminuir, remover ou manter os estímulos, visando aumentar a capacidade da mãe de responder positivamente pelas respostas adaptáveis. As intervenções de enfermagem envolvem conversar com a mãe, orientar e esclarecer suas dúvidas quanto à doença do filho, estar atento aos sinais de insegurança e dúvidas que ela apresenta durante a hospitalização do filho, a fim de responder às suas inquietações.

Avaliação: a última fase do processo envolve a verificação da eficácia das intervenções de enfermagem em relação ao comportamento da pessoa, isto é, se o objetivo estabelecido foi atingido. O enfermeiro, para avaliar o comportamento da mãe realiza uma observação do seu comportamento e conversa para saber como ela está se sentindo, para verificar se a diminuição do seu nível de ansiedade foi atingido, chegando a um comportamento eficaz.

A Figura 1 ilustra como as etapas do processo de enfermagem se articulam para alcançar os comportamentos adaptativos.

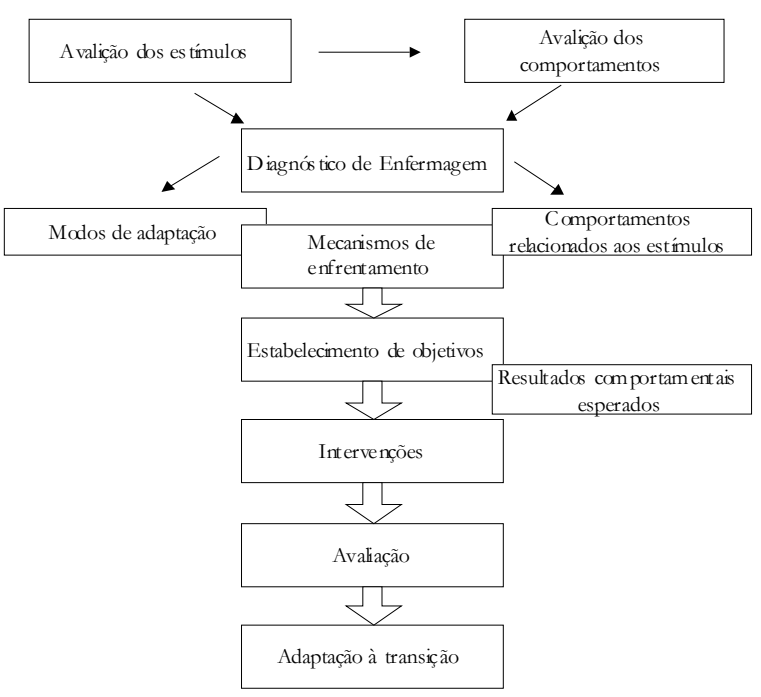

Figura 1 - Representação do modelo de cuidado transicional às mães, articulado aos modos de adaptação propostos por Roy ${ }^{(2)}$

\section{DISCUSSÃO}

Aliar um referencial teórico e metodológico ao cuidado de mães que vivenciam uma experiência singular de ter seu filho hospitalizado com doença cardíaca congênita exigiu dedicação e aprofundamento do conhecimento, pois ao desvelar suas expressões sobre a experiência foi possível mergulhar em seu mundo vivido de forma intensa, apreendendo modos de adaptação como os fisiológicos, de interdependência, autoconceito e função de papel. A mãe durante todo o processo de hospitalização e vivência da transição de saúde-doença do filho está exposta a estímulos que ativam os mecanismos de resistência reguladores e cognitivos da pessoa para manter a adaptação. As respostas são os comportamentos da pessoa que 
podem ser adaptáveis ou ineficazes.

É possível perceber, nitidamente, quanto os estímulos afetam os modos de adaptação do ser mãe nessa situação, pois todos foram relatados e relacionados como formas de enfrentamento para obter uma resposta de adaptação. Nesse momento, o cuidado transicional é acionado pelo enfermeiro que, aliado aos conhecimentos teóricos da teoria de enfermagem de Roy, mobiliza recursos do enfermeiro e da mãe, para juntos ultrapassarem as barreiras que impedem uma adaptação eficaz.

Somente a sensibilidade do enfermeiro pode reconhecer as necessidades de cada ser mãe em distintas situações. Essa sensibilidade, somada ao modelo de cuidado transicional às mães oferece o suporte, o amparo, a solidariedade para chegar ao outro lado, como ser adaptado. A percepção, pelo enfermeiro, das reações da mãe é que direciona o cuidado, o qual deve ser congruente, a cada demanda em especial, para avaliar os mecanismos em ação e resultar em respostas de adaptação.

\section{CONCLUSÃO}

Compreender o que significa para a mãe vivenciar o processo de transição de doença-saúde do filho com cardiopatia congênita representou um desafio, o qual conseguimos alcançar e nos permitiu ampliar o olhar sobre os modelos tradicionais de cuidado, que entendem somente o paciente como foco de atenção do enfermeiro. Foi possível visualizar a mãe como uma extensão dos cuidados de enfermagem, buscando atender às suas necessidades, enquanto acompanha a vivência da transição de saúde-doença de seu filho hospitalizado.

Ao concluir este estudo percebemos que o significado para a mãe, sobre a vivência do processo de transição de saúde-doença do filho com cardiopatia congênita, é muito maior do que apenas estar ao lado do filho e acompanhálo durante sua hospitalização, é sentir-se internada com

\section{REFERÊNCIAS}

1. Forte TL, Sato CM. Programa família participante: a humanização hospitalar como resgate da dignidade, exercício da cidadania e transformação da gestão hospitalar. Curitiba: Associação Hospitalar de Proteção a Infância Dr. Raul Carneiro/ Hospital Pequeno Príncipe; 2006.

2. BrandalizeDL. Cuidadode enfermagemàmãena vivência doprocesso de transição de saúde-doença do filho com cardiopatia congênita [dissertação]. Curitiba: Universidade Federal do Paraná; 2007.

3. Guiller CA, Dupas G, Pettengill MAM. Criança com anomalia congênita: estudo bibliográfico de publicações na área de enfermagem pediátrica. Acta Paul Enferm. 2007; 20(1):18-23.

4. Nettina SM. Prática de enfermagem. 6a ed. Rio de Janeiro: Guanabara Koogan; 1999.

5. Zagonel IPS. O cuidado humano transicional na trajetória de enfermagem. Rev Latinoam Enferm. 1999;7(3):25-32.

6. Roy SC, Andrews HA. Teoria da enfermagem. O modelo de adaptação de Roy. Lisboa: Instituto Piaget; 2001. ele, compartilhar dos seus sofrimentos, doar-se, é abrir mão de sua própria vida, seus sentimentos, suas necessidades, é dar-se completamente em favor do filho que sofre, até sua total recuperação.

Também verificamos, ao identificar os comportamentos apresentados pelas mães relacionados a cada modo de adaptação propostos por Roy, que em três dos quatro modos de adaptação as mães apresentam comportamentos ineficazes, pois, à medida que se dedicam ao cuidado ao filho, vão deixando o cuidado de si e da sua familia de lado, e todo o seu contexto de vida sofre alterações. $\mathrm{O}$ modo de adaptação que revelou comportamentos eficazes das mães foi o de interdependência, visto que elas procuram o relacionamento interpessoal como uma forma de suporte, de apoio nesse momento que vivenciam, demonstrando a tentativa de se adaptarem, mesmo que seja em um só modo de adaptação.

$\mathrm{O}$ enfermeiro, ao conhecer o processo de transição vivenciado pela mãe e as repercussões que o mesmo traz à sua vida, pode auxiliá-la a reconhecer os estímulos que estão influenciando em cada modo de adaptação, e ajudála a mobilizar os recursos que possui, tanto internos quanto externos, para o enfrentamento e adaptação.

Dessa forma, destacamos a importância deste trabalho em apresentar um modelo de cuidado transicional, articulado aos modos de adaptação propostos por Roy. Este modelo visa propor uma forma de cuidado individual e singular à mãe, baseado em suas reais necessidades, e que a conduza à adaptação por meio de respostas eficazes.

Os resultados encontrados com a análise contribuem para novas reflexões sobre esta temática, tendo em vista o aprimoramento do cuidado e o despertar para novas práticas de cuidar do enfermeiro a este grupo. Por meio do pensar e do refletir é que o enfermeiro pode alcançar as transformações tão desejadas em sua prática profissional, tornando-a consistente, inovadora e com qualidade, a partir de referenciais teóricos aliados à prática, tendo como foco o ser humano.

7. Neves EP, Zagonel IPS. Pesquisa-cuidado: uma abordagem metodológica que integra pesquisa, teoria e prática em enfermagem. In: I CIBRAPEQ, I Conferência Internacional do Brasil de Pesquisa Qualitativa. Taubaté (SP): Centro de Convenções Amácio Mazzaropi, 24 a 27 de março de 2004. [CD ROOM]. Taubaté: Núcleo de Pesquisa da Família. Departamento de Psicologia da Universidade de Taubaté; 2004. p. 813-20.

8. Brasil. Ministério da Saúde. Conselho Nacional de Saúde. Resolução $n^{\circ}$ 196/96 sobre pesquisa envolvendo seres humanos. Brasilia: Ministério da Saúde / Conselho Nacional de Saúde; 1996.

9. Bardin L. Análise de conteúdo. Rio de Janeiro: Edições 70; 1991.

10. Melo EM, Silva RM, Fernandes AFC. O relacionamento familiar após a mastectomia: um enfoque no modo de interdependência de Roy. Revista Brasileira de Cancerologia. 2005;51(3):219-25.

11. Milanesi K, Collet N, Oliveira BRG, Vieira CS. Sofrimento psíquico da família de crianças hospitalizadas. Rev Bras Enferm. 2006;59(6):769-74. 